\title{
Trabalhonecessário
}

Issn: 1808 - 799X

ano 12 , no $18-2014$

Apresentação

\section{POR QUE THOMPSON?}

É com imensa satisfação que apresentamos o dossiê Trabalho, história e experiência de classe: Thompson 50 anos depois - por nós organizado -, no número 18 da Revista Trabalho Necessário, revista que se pauta nos fundamentos do materialismo histórico para analisar as relações entre trabalho e educação, tendo em conta a historicidade dos processos de produção da existência humana.

Com Karel Kosik (1976), entendemos que a compreensão da realidade não ocorre a partir da mera reflexão sobre sua aparência imediata. Para compreendê-la, torna-se necessário buscar o que se esconde por detrás dos fenômenos, de modo a destruir o mundo da pseudoconcreticidade - mundo do claro-escuro de engano e verdade - que é, também, o mundo da realidade onde a essência nele se manifesta. Para o filósofo tcheco, o desafio está em captar os elementos mais concretos, as objetivações que explicam a totalidade social, não por meio de ligações simples, mas sim por meio da conexão que engloba os objetos relacionados em seu desenvolvimento no tempo e no espaço. Se o concreto é concreto porque é a síntese de múltiplas determinações, quanto maior o número de campos do real que a ciência descrever, maior será a possibilidade de se aproximar da realidade, da unidade do diverso.

TrabalhoNecessário - www.uff.br/trabalhonecessario; Ano 12, № 18/2014. 


\section{Trabalhonecessário \\ Issn: 1808 - 799X \\ ano $12, \mathrm{n}=18-2014$}

Como pesquisadores que insistem na necessidade da superação de relações sociais fundadas na exploração dos seres humanos e na apropriação privada (e indevida) da natureza; como pessoas que, de diferentes maneiras, lutam pela emancipação da classe trabalhadora do jugo do capital (e de qualquer outra forma de dominação), cabe-nos contribuir para tornar ainda mais visíveis os movimentos do real, nos quais a história se move e, com ela, as relações entre capital, trabalho e educação.

Esse tem sido o compromisso ético-político do Neddate - Núcleo de Estudos, Documentação e Dados sobre Trabalho e Educação! E é nesta perspectiva que a Revista Trabalho Necessário traz a público o conjunto de oito artigos que versam sobre o pensamento de Edward Palmer Thompson, historiador marxista inglês.

Por que Thompson? Aqui, no espaço da apresentação deste dossiê, não temos a pretensão de elencar suas diversas contribuições teóricometodológicas para campo Trabalho e Educação e outros campos do conhecimento. Entretanto, no intuito de convidar os leitores para apreciar os artigos que nos brindam os pesquisadores, ressaltamos, a título de introdução, alguns aspectos do seu pensamento.

Sobre os movimentos da vida real e suas múltiplas determinações, Thompson (1981) nos ensina que a História precisa ser entendida como um processo estruturado, cujas mediações estão carregadas de elementos contraditórios. Processo estruturado de tal modo que, tem por base (ou infraestrutura) relações sociais de produção hegemônicas em determinados espaços/tempos históricos. Sem desconhecer e desconsiderar as determinações econômicas que tornam um dado modo de produção hegemônico, e colocando-se contrário ao perigo do "reducionismo econômico", este autor convida-nos a perceber que, no processo histórico, entram em cena outras determinações, em especial, as da agência humana. Afinal, é pela

TrabalhoNecessário - www.uff.br/trabalhonecessario; Ano 12, № 18/2014. 


\section{Trabalhonecessário \\ Issn: $1808-799 \mathrm{X}$ \\ ano 12, no $18-2014$}

práxis, é pela capacidade de ação/pensamento/ação, ou seja, é pela própria agência humana que se dá a possibilidade de criação e recriação da realidade humano-social.

Importante enfatizar que, embora a categoria práxis seja pouco mencionada, esta é, sem dúvida, uma categoria fortemente presente em sua na obra de Edward Thompson. Em uma leitura atenta é possível perceber que, a metáfora do "gorila amestrado", empregada por Antonio Gramsci, Ihe serve como recurso para defender a ideia de práxis como unidade indissolúvel entre ação e pensamento (THOMPSON, 1981).

Historiador marxista que investiga o(s) mundo(s) do trabalho, Thompson tem como eixo de análise os movimentos do real, tendo como referência as mediações que conformam as particularidades e singularidades de uma totalidade social, historicamente determinada. Ressaltamos que, em $A$ formação da classe operária inglesa (THOMPSON, 1987), o autor focaliza contextos históricos dos anos 1790 a 1830, em que a gentry (burguesia fundiária), em aliança com o capital comercial e industrial, coloca em cheque a produção voltada para subsistência, promovendo a ruptura entre local de vida e local de trabalho, entre tempo livre e tempo de trabalho. Em outras palavras, Thompson evidencia que, o pacto burguês retira dos trabalhadores e trabalhadoras a autonomia para definir a pauta e a rotina do tempo socialmente necessário para produzir sua existência, do qual o lazer e ócio fazem parte.

Ao compreender classe social não como uma categoria estática, mas sim como uma formação cuja historicidade deriva de relações vividas no processo de produção da vida social, Edward Palmer Thompson traz à superfície as maneiras pelas quais homens e mulheres da plebe resistem e confrontam seu modo de vida particular com aquele requerido pela Revolução industrial. Nesse contexto, ganham relevância, na análise de Thompson, a cultura popular, o autodidatismo dos trabalhadores e as aprendizagens

TrabalhoNecessário - www.uff.br/trabalhonecessario; Ano 12, № 18/2014. 


\section{Trabalhonecessário \\ Issn: 1808 - 799X \\ ano 12 , no $18-2014$}

coletivas como elementos de educação política. Entendendo ser a prática a fonte primeira de conhecimentos e por não desconsiderar o que, hoje, denominamos de "saberes da experiência" ou de "saberes populares", em uma passagem da Miséria da Teoria, o historiador enfatiza que os

\footnotetext{
conhecimentos se formaram, e ainda se formam fora dos procedimentos acadêmicos. $\mathrm{E}$ tampouco eles têm sido, no teste da prática, desprezíveis. Ajudaram homens e mulheres a trabalhar nos campos, a construir casas, a manter complicadas organizações sociais, e mesmo, ocasionalmente, a questionar eficazmente as conclusões do pensamento acadêmico (THOMPSON, 1981, p. 17).
}

Sem menosprezar as determinações econômicas, culturais e educacionais impostas pela burguesia, como classe em ascensão, Thompson torna visível o lugar dos sujeitos individuais e coletivos na história. Mais do que compreender a história dos vencedores, o historiador marxista quer captar a "história vista de baixo". Para tal, elege fontes documentais que trazem à tona a agência de mulheres e homens trabalhadores que se organizam para defender sua forma de viver, em oposição às relações sociais de produção e reprodução da vida impostas pela classe que detém a hegemonia cultural.

Na perspectiva do "método da lógica histórica" que privilegia o diálogo entre conceito e evidência, Thompson envereda por outros mundos do trabalho, concluindo de seus estudos empíricos, fundamentados na concepção materialista da história, que os trabalhadores não foram vítimas passivas das mudanças ocorridas no século XVIII. Ao contrário! Resistiram intensamente ao longo do processo de constituição do modo de produção capitalista.

O historiador considera que a luta de classe é sempre luta por defesa de valores; assim, a luta pela preservação dos costumes se dá em um campo tenso de conflitos. No contexto da Inglaterra do Século XVIII, ganham evidência a "economia moral" e outras manifestações da cultura popular, as quais podem

TrabalhoNecessário - www.uff.br/trabalhonecessario; Ano 12, № 18/2014. 


\section{Trabalhonecessário}

Issn: 1808 - 799X

ano 12 , no $18-2014$

ser consideradas como experiência de classe e elemento fundamental do "fazer-se" classe operária inglesa (THOMPSON, 1998).

Para ele, "economia" e "cultura" não representam momentos estanques da "base" e "superestrutura"; a cultura não está á reboque dos fenômenos econômicos, mas se constitui na mesma rede de relações (THOMPSON, 2001). Nesse sentido, a classe social deve ser analisada tanto como formação econômica quanto cultural, tal qual ele assinala em Algumas observações sobre classe e consciência de classe:

A classe se delineia segundo o modo como homens e mulheres vivem suas relações de produção e segundo a experiência de suas situações determinadas, no interior do "conjunto de suas relações sociais", com a cultura e as expectativas a eles transmitidas e com base no modo pelo qual se valeram dessas experiências em nível cultural. (THOMPSON, 2001, p. 277).

Não por mero diletantismo acadêmico, a passagem dos 50 anos da publicação de $A$ formação da classe operária inglesa precisa ser (re)conhecida e rememorada. Sem dúvida, Thompson estava realmente convencido de que é necessário investigar a história do ponto de vista dos "de baixo". Ele nos ensina que a preservação da tradição e dos costumes, que substanciavam o "direito consuetudinário" denotam uma "consciência costumeira", necessária para manter um modo de vida cuja racionalidade não coincidia com a racionalidade das relações de produção capitalista. Por isso, na Introdução do livro Costumes em Comum, Thompson enfatiza que devemos colocar em dúvida a ideia do "homem econômico" como a nova natureza humana criada pelo capitalismo. Adverte que, se por um lado, "nunca retornaremos à natureza humana précapitalista", de outro, "lembrar como eram os seus códigos, expectativas e necessidades alternativas, pode renovar nossa percepção sobre a gama de possibilidades implícitas no ser humano" (THOMPSON, 1998, p. 23).

TrabalhoNecessário - www.uff.br/trabalhonecessario; Ano 12, № 18/2014. 


\section{Trabalhonecessário \\ Issn: 1808 - 799X \\ ano 12, no $18-2014$}

Para rememorar os 50 anos de $A$ formação da classe operária na Inglaterra e os 20 anos da morte do historiador, promovemos, em setembro de 2013, o Seminários Neddate sobre a temática Trabalho, história e experiência de classe: Thompson 50 anos depois. Nesse seminário, nossa intenção foi promover 0 intercâmbio entre pesquisadores da Universidade Federal Fluminense (UFF) e de outras universidades que se situam no âmbito do Estado do Rio de Janeiro, a saber: Universidade do Estado do Rio de Janeiro (UERJ), Universidade Federal do Estado do Rio de Janeiro (UNIRIO) e Universidade Federal Rural do Rio de Janeiro (UFRRJ). Dito de outra maneira, nosso objetivo foi reunir pesquisadores, professores, estudantes de graduação e pós-graduação, além de outros estudiosos do pensamento de E.P.Thompson, geograficamente próximos do espaço físico do Neddate, situado na Faculdade de Educação da UFF, em Niterói, de modo a favorecer a discussão sobre o "estado da arte" de nossas pesquisas.

O Seminários Neddate foi, de fato, um momento muito rico! Os artigos que se seguem são derivados das falas, intervenções dos palestrantes e mediadores, a quem mais uma vez agradecemos.

Seguindo os fundamentos teórico-metodológicos de Edward Palmer Thompson, embora este ou aquele autor/a privilegie este ou aquele conceito para analisar o pensamento do historiador marxista, as categorias ou conceitos (entendidos por ele como sinônimos) são analiticamente tratados como "conceitos de junção" (THOMPSON, 1981). Nessa perspectiva, a apreensão da totalidade de seu pensamento requer a necessária articulação de palavraschave que perpassam o conjunto de artigos: cultura popular, luta de classes, classe, educação e experiência, experiência de classe, consciência de classe, economia e cultura.

Neste dossiê Trabalho, história e experiência de classe: Thompson 50 anos depois, os leitores não terão dificuldade de perceber que, para além dos

TrabalhoNecessário - www.uff.br/trabalhonecessario; Ano 12, № 18/2014. 


\section{Trabalhonecessário \\ Issn: 1808 - 799X \\ ano $12, \mathrm{n}=18-2014$}

muros da academia, a produção teórica do autor está visceralmente articulada à sua trajetória política, quer como membro do Grupo de Historiadores do Partido Comunista da Grã-Bretanha, quer como militante da Campanha pelo Desarmamento Nuclear (CND) quer como editor do jornal The New Reasoner, que deu origem ao movimento político que ficou conhecido como Nova Esquerda. Sem falar dos seus 17 anos de militância como professor de jovens e adultos; e também de sua participação na criação da Associação Educacional de Trabalhadores, com objetivo de socializar e defender os valores da cultura operária,em contraposição aos valores da burguesia.

Mas, deixemos que os próprios autores e autoras, que nos brindam neste dossiê possam melhor nos informar sobre as contribuições teóricometodológicas de Edward Palmer Thompson.

O historiador e pesquisador Marcelo Badaró Mattos (UFF) apresenta o artigo $A$ formação de classe operária inglesa: história e intervenção, no qual recupera a repercussão internacional e o impacto da obra de Thompson no Brasil, indicando que suas contribuições no campo histórico/historiográfico tiveram origem no debate teórico e na militância política. Tendo como referência, escritos anteriores a 1963, compara-os às ideias-chave do clássico A formação da classe operária inglesa. Considera, entre outros, que o respeito à experiência dos trabalhadores é uma chave fundamental para que possamos compreender de que forma a atividade de Thompson como professor de Literatura Inglesa e História foi um elemento central de seu aprendizado prévio à redação de $A$ formação. Conclui que 0 historiador marxista recusa explicações simplistas e dogmáticas do processo histórico, as quais correspondiam a opções políticas e teóricas que, no seu entender, atravancavam as lutas da classe trabalhadora.

No artigo intitulado Edward P. Thompson: método, categorias analíticas e fenômenos educacionais, a pesquisadora Zuleide S. Silveira (UFF) analisa o

TrabalhoNecessário - www.uff.br/trabalhonecessario; Ano 12, № 18/2014. 


\section{Trabalhonecessário \\ Issn: 1808 - 799X \\ ano $12, \mathrm{n}=18-2014$}

método do materialismo histórico dialético à luz das contribuições teóricometodológicas do historiador inglês, tendo em conta seu debate sobre a "lógica histórica" e sua contraposição aos métodos marxista-estruturalista, marxistaexistencialista, bem como os equívocos que consistem em separar a dimensão cultural da dimensão social e estas dos fenômenos econômicos. Com base nas categorias luta de classes, classe social, consciência de classe, cultura e experiência, argumenta sobre a pertinência do contributo thompsoniano para a investigação dos fenômenos educacionais. A autora entende que a investigação empreendida por Thompson, observada em $A$ formação da classe operária inglesa e em outros escritos, sublinha a investidura no necessário diálogo empírico; e análise crítica de informações produzidas por instituições oficiais sobre a classe trabalhadora.

A seguir, dois artigos se complementam e contemplam nossas indagações sobre a existência ou não de uma perspectiva emancipatória na obra do historiador marxista. Para responder a esta pergunta, nada melhor do que proceder à reconstrução histórica da categoria emancipação.

Assim, em Emancipação: a historicidade do conceito e a polêmica no processo real da existência humana, a professora Maria Ciavatta (UFF) faz a reconstrução histórica do conceito, recuperando concepções de autores que têm se debruçado sobre o sentido do termo. Para ela, a emancipação individual ou coletiva supõe a conquista de liberdade, de autonomia pelos sujeitos sociais; no entanto, liberdade e autonomia são abstrações, se não forem remetidos à historicidade das condições de produção da vida humana. Compreende que totalidade social é uma categoria indispensável, pois somente através do conhecimento da totalidade histórica dos processos que almejam a emancipação podemos avaliar as possibilidades de sua efetivação, tendo em conta o potencial dos sujeitos envolvidos e as relações de força para a construção de uma nova hegemonia.

TrabalhoNecessário - www.uff.br/trabalhonecessario; Ano 12, № 18/2014. 


\section{Trabalhonecessário \\ Issn: 1808 - 799X \\ ano 12, no $18-2014$}

Outro artigo que nos ajuda a inferir sobre o caráter emancipador da obra de Thompson é o da pesquisadora Alessandra Frota Martinez de Schueler (UFF), intitulado Educação, experiência e emancipação: contribuições de E.P. Thompson para a história da educação. Nele, a autora recupera a trajetória profissional e a prática teórica ativa do historiador no âmbito do materialismo histórico e da História Social inglesa. Para ela, a "educação do desejo" pela vida era essência do trabalho político e cultural de E. P. Thompson; sua utopia era despertar os jovens, homens e mulheres comuns para a vida, para a compreensão crítica de sua história e de sua ação concreta no mundo. Assim, a produção do autor tem importância fundamental para os estudos que buscam compreender os processos históricos e as práticas educativas, as experiências e as lutas pela emancipação humana e a transformação social e política.

Em E. P. Thompson, a historiografia brasileira e a valorização das experiências dos trabalhadores, Marcelo Mac Cord (UFF) ressalta a necessidade uma história brasileira "vista de baixo", o que requer a valorização de experiências passadas e presentes da classe trabalhadora. Enfatiza a importância de se aprender a compreender os "de baixo", ou seja, os trabalhadores, considerando seus valores, sem julgá-los aprioristicamente como típicos ou atípicos, de acordo com os dogmas teóricos. Questiona as perspectivas mecanicistas e maniqueístas presentes nas análises de "classe em si" e "classe para si". Tais análises, segundo o autor, leva ao entendimento de que somente nos sindicatos e nos atuais partidos operários as classes subalternas atingem a "consciência" de que haviam sido "alienadas" de sua "real identidade" e da "realidade" que a cerca. Para Mac Cor, na atualidade, o ativismo social do marxista inglês é deveras inspirador para projetos de extensão universitária que objetivam a educação de trabalhadores precarizados.

TrabalhoNecessário - www.uff.br/trabalhonecessario; Ano 12, № 18/2014. 


\section{Trabalhonecessário \\ Issn: 1808 - 799X \\ ano $12, \mathrm{n}^{\circ} 18-2014$}

Em seguida, no artigo Características e fundamentos da concepção thompsiniana de cultura e repercussões na educação, as pesquisadoras

\section{Angela Maria Souza Martins (UNIRIO) e Lúcia Maria Wanderley Neves}

(Coletivo de Política Educacional) têm com referência seus estudos sobre a concepção marxista de cultura, realizados com base nas construções teóricas de Antonio Gramsci, Edward Thompson e Raymond Williams. As autoras ressaltam o modo como Edward $P$. Thompson concebe a relação entre base e superestrutura, entre ser social e consciência social e a importância, por ele atribuída, à interface entre experiência, hegemonia e cultura na construção e na dinâmica do ser social. Para ele, as alterações no processo histórico não se circunscrevem apenas às mudanças no desenvolvimento das forças produtivas, mas também aos movimentos e formas de expressão populares. As autoras entendem que, dependendo do nível de organização das classes subalternas e das experiências de construção de novas relações sociais, a educação pode ter um papel privilegiado na construção de um projeto de transformação do ser social.

Por sua vez, em A ideia de cultura e a experiência na Feira de São Cristóvão: delineando caminhos, Rafaela De Souza Ribeiro (UNIRIO) convidanos a adentrar na contemporaneidade das relações entre trabalho e capital que, no contexto do regime de acumulação flexível, se manifestam em um tradicional espaço cultural da cidade do Rio de Janeiro, situado no bairro histórico de São Cristóvão. Para a autora, torna-se urgente desvendar os novos significados e o lugar da cultura, em especial, o da cultura popular representada pelos feirantes nordestinos, tendo em conta o amplo material que contempla a literatura de cordel, comidas e músicas típicas. Ao focalizar o espaço de trabalho dos feirantes, artistas, músicos e artesãos, considera que a cultura assume um papel central na experiência da classe trabalhadora.

TrabalhoNecessário - www.uff.br/trabalhonecessario; Ano 12, №18/2014. 


\section{Trabalhonecessário \\ Issn: 1808 - 799X \\ ano 12, no $18-2014$}

Finalizando o conjunto de textos que compõem este dossiê, a pesquisadora Eveline Algebaile (UERJ) apresenta o artigo intitulado $O$ legado de Thompson para a pesquisa sobre políticas públicas. Para ela, as políticas públicas não as circunscrevam às suas configurações oficiais e a suas aparentes cristalizações, o que nos anuncia a necessidade de se considerar, na análise das formas institucionalizadas, a heterogeneidade, as variações e as instabilidades que presidem e põem em permanente movimento os processos de institucionalização. Argumenta que a ênfase dada por Thompson às tensões, contradições, fraturas e oposições, que se constituem no curso da história, permitem evidenciar o presente e o futuro como realidades em produção. Isto favorece formas de compreensão crítica capazes de reconhecer, nos processos em curso de discussão, formulação, implementação e acompanhamento de políticas públicas, as condições objetivas reais de disputa contra-hegemônica de seus sentidos.

Para finalizar, gostaríamos de registrar, mais uma vez, a satisfação de apresentar aos leitores da Revista Trabalho Necessário, o dossiê Trabalho, história e experiência de classe: Thompson 50 anos depois. Nos oito artigos, os autores e autoras evidenciam não serem poucas as contribuições teóricometodológicas do historiador marxista inglês para o campo Trabalho e Educação e para os demais campos de conhecimento da realidade humanosocial.

Assim como o filósofo tcheco Karel Kosik (1976), a quem nos reportamos no início desta apresentação, vislumbramos que vale a pena, para pesquisadores/trabalhadores, enveredar nas diversas dimensões do mundo real. Importante não perder de vista a totalidade social, a compreensão da história como processo estruturado, como síntese de múltiplas determinações e, em especial as determinações da agência humana, vividas individual e coletivamente como experiências de classe.

TrabalhoNecessário - www.uff.br/trabalhonecessario; Ano 12, № 18/2014. 


\section{Trabalhonecessário}

Issn: 1808 - 799X

ano 12, no $18-2014$

Não por acaso, a passagem dos 50 anos da publicação de $A$ formação da classe operária inglesa precisa ser (re)conhecida e rememorada. Não foi a esmo que o Seminários Neddate, realizado, em setembro de 2013, elegeu o pensamento de Edward Palmer Thompson como objeto de reflexão e inspiração. Para concluir a apresentação desse dossiê, recuperarmos um trecho da exposição do Prof. Dr. Marcelo Badaró Mattos (UFF), que nos deu a honra de proferir a Conferência de Abertura.

Sobre A formação da classe operária inglesa comenta:

Face à falta de credenciais acadêmicas do Thompson, a repercussão positiva que o livro foi uma surpresa. Rapidamente o livro se transformou em uma obra de referência para a história da classe trabalhadora inglesa e para os estudos sobre a História do Trabalho de uma forma geral. A companheira de décadas da vida do Thompson, Dorothy Thompson, disse numa entrevista: 'Nos ficamos surpresos com a recepção que o livro do Edward teve. Não podíamos acreditar que mais ninguém à nossa volta fosse dar a ele uma opinião favorável'. [Isto porque], o livro anterior que Thompson publicou, tinha recebido umas resenhas na última página de um caderno obscuro. E $A$ Formação da Classe Operária Inglesa, de repente, se transforma como padrão das ciências humanas, quase que em um best seller. (Marcelo Badaró Mattos, 23/09/2013)

A todos e todas, desejamos uma boa leitura!

Niterói, junho de 2014.

Lia Tiriba ${ }^{1}$

1 Professora do Programa de Pós-Graduação em Educação da Universidade Federal Fluminense. Coordenadora do Neddate - Núcleo de Estudos, Documentação e Dados sobre Trabalho e Educação.

TrabalhoNecessário - www.uff.br/trabalhonecessario; Ano 12, № 18/2014. 


\section{Trabalhonecessário}

Issn: 1808 - 799X

ano 12 , no $18-2014$

\section{Referências}

KOSIK, Karel. A dialética do concreto. Rio de Janeiro: Paz e Terra, 1976.

THOMPSON, Edward P. As peculiaridades dos ingleses e outros artigos. Organizadores: Antonio Luigi Negro e Sergio Silva. Campinas, São Paulo: Editora da UNICAMP, 2001.

THOMPSON, Edward P. Costumes em Comum. Estudos sobre a cultura popular tradicionalSão Paulo: Companhia das Letras, 1998.

THOMPSON, Edward P. A formação da classe operária inglesa: a árvore da liberdade, vol. 1. Rio de Janeiro: Paz e Terra, 1987.

THOMPSON, Edward P. A miséria da teoria ou um planetário de erros. Rio de Janeiro: Paz e Terra, 1981.

TrabalhoNecessário - www.uff.br/trabalhonecessario; Ano 12, № 18/2014. 